\title{
A Paradigm Shift in Functional Brain Imaging
}

\author{
Marcus E. Raichle \\ Departments of Radiology and Neurology, Washington University School of Medicine, St. Louis, Missouri 63110
}

\section{Introduction}

The history of brain imaging has paralleled the growth of the Society for Neuroscience, from its inception in 1973 with the introduction of $\mathrm{x}$-ray computed tomography $(\mathrm{CT})$ to the present (for a historical review, see Webb, 1990; Kevles, 1997; Raichle, 2000; Raichle, 2009). Since then, imaging of the human brain, first with positron emission tomography (PET) and now with magnetic resonance imaging (MRI), has become an increasingly important part of research in neurosciences, as well as the social sciences, and also an important face for brain research in the lay community. The thirst for information about brain function is universal, and imaging, for better or worse, has been used by many as a medium for the discussion.

Growth in functional imaging research has been particularly exceptional. Since its introduction in 1992 (Bandettini et al., 1992; Frahm et al., 1992; Kwong et al., 1992; Ogawa et al., 1992), functional MRI (fMRI) has accounted for nearly 12,000 papers along with 10,000 additional papers using PET, according to PubMed searches using the terms ["fMRI" and "brain"] and ["PET" and "brain"].

Functional brain imaging has followed a long tradition in neuroscience: studying neuronal responses to stimuli and activity during task performance. In this work, the role of bottom-up versus top-down (or feed-forward vs feed-back) causality is frequently discussed, reflecting a debate that extends back at least a century on the relative importance of intrinsic and evoked activity in brain function [for a comprehensive historical review, see Chapter 1 in the book by Llinas (2001)]. "Intrinsic activity" is ongoing neural and metabolic activity that is not directly associated with subjects' performance of a task. The distinction between intrinsic activity and task-evoked activity applies at many levels of neurophysiological examination, including events at the cellular level where ion channel proteins, receptors, and the components of signal transduction pathways turn over with half-lives of minutes, hours, days, and weeks (Marder and Goaillard, 2006). Brain imaging has recently entered this discussion with information that will likely be important in shaping future research. It

Received Sept. 2, 2009; accepted Sept. 3, 2009.

Correspondence should be addressed to Marcus E. Raichle, Department of Radiology, Washington University School of Medicine, 4525 Scott Avenue, St. Louis, M0 63110. E-mail: marc@npg.wustl.edu.

D01:10.1523/JNEUROSCI.4366-09.2009

Copyright $\odot 2009$ Society for Neuroscience ～0270-6474/09/2912729-06\$15.00/0 suggests to me an impending paradigm shift (Kuhn, 1996) brought about by surprising discoveries in imaging research that have occurred against a background of complementary work in electrophysiology and cell biology. In this essay I briefly review evidence that persuades me of this view.

\section{Two views of brain function}

Since the beginning of the 20th century and possibly earlier, two views of brain function have existed (Llinas, 2001). One view, pioneered by the early work of Sherrington (1906), posits that the brain is primarily reflexive, driven by the momentary demands of the environment. The other view is that the brain's operations are mainly intrinsic, involving the acquisition and maintenance of information for interpreting, responding to, and even predicting environmental demands, a view introduced by a disciple of Sherrington, T. Graham Brown (1914) [for a view of his work in a modern context, see the study by Yuste et al. (2005)]. The former has motivated most neuroscience research including that with functional neuroimaging. This is not surprising because experiments designed to measure brain responses to various stimuli and carefully designed tasks can be rigorously controlled, whereas evaluating the behavioral relevance of intrinsic activity can be an elusive enterprise. How do we adjudicate the relative importance of these two views in terms of their impact on brain function?

One means of evaluating the relative importance of evoked and intrinsic activity is to examine their cost in terms of brain energy consumption. In the average adult human, the brain represents $\sim 2 \%$ of the total body weight but accounts for $20 \%$ of all the energy consumed (Clarke and Sokoloff, 1999). This highenergy consumption occurs in the resting state, a behavioral state characterized by quiet repose with either eyes closed or open, with or without visual fixation. Furthermore, relative to the very high rate of ongoing or "basal" energy consumption in humans, the additional energy consumption associated with evoked changes in brain activity is remarkably small, often $<5 \%$ (Raichle and Mintun, 2006). This low figure likely applies to stimulusindependent thoughts (i.e., day dreaming) as well. From these data, it is clear that the brain's enormous energy consumption is little affected by task performance, an observation first made more than 50 years ago (Sokoloff et al., 1955) [for prescient early insights, the interested reader may also wish to read Creutzfeldt (1974)]. 
What is the nature of this ongoing intrinsic activity that commands such a large amount of the brain's energy resources? Measurements of brain energy metabolism using magnetic resonance spectroscopy (Sibson et al., 1997; Sibson et al., 1998; Shulman et al., 2001, 2004) in a variety of experimental settings have indicated that $60-80 \%$ of overall brain energy consumption is devoted to glutamate cycling and, hence, neuronal signaling. Complementary analyses using extant anatomic, physiologic, and metabolic data (Wong-Riley, 1989; Ames, 2000; Attwell and Laughlin, 2001; Lennie, 2003) to assess the cost of different components of excitatory signaling in the gray matter have arrived at similar conclusions. Such estimates leave for future consideration the demands placed on the brain's energy budget by the functional activity of inhibitory interneurons (Ackermann et al., 1984; McCasland and Hibbard, 1997; Waldvogel et al., 2000; Chatton et al., 2003; Patel et al., 2005; Buzsáki et al., 2007) and astrocytes (Pellerin and Magistretti, 1997; Magistretti and Chatton, 2005). That evidence notwithstanding, it is likely to remain the case that the majority of brain energy consumption is devoted to functionally significant intrinsic activity. The challenge, of course, is how to study these intrinsic brain processes. Functional brain imaging has provided some intriguing new insights.

\section{Exploring intrinsic activity}

It was a chance observation in neuroimaging, first with PET and later with $\mathrm{AMRI}$, that actually provided a new perspective on what to look for in studying the brain's intrinsic activity. This was the occurrence of activity decreases during the performance of goaldirected tasks when compared with the resting state.

The first formal characterization of task-induced activity decreases from a resting state was a large meta-analysis of published PET data from our group (Shulman et al., 1997). This study generated a set of iconic images of a constellation of brain regions now generally referred to as the default mode network or DMN (Fig. 1A) after our later paper on a default mode of brain function (Raichle et al., 2001) [for a historical perspective, see Raichle and Snyder (2007)]. The unique identity of this group of brain regions was amply confirmed in later meta-analyses by Jeffery Binder et al. (1999) at the Medical College of Wisconsin and Bernard Mazoyer et al. (2001) in France. Similar observations are now an everyday occurrence in laboratories throughout the world, leaving little doubt that the specific brain areas that make up the DMN, decrease their activity across a remarkably wide array of task conditions when compared with a passive control condition such as visual fixation. From this work has come an increasing appreciation of the many unique features of this network of areas [for example, see the studies by Buckner et al. (2008), Hagmann et al. (2008)].

The discovery of the DMN provided a new, large-scale view of the organization of the brain's intrinsic activity. However, the need for more detailed studies of intrinsic activity at a scale sug- gested by the DMN was apparent. It was the discovery that the large-scale network organization of intrinsic activity also emerges from the study of patterns of spatial coherence in the spontaneous fluctuations (i.e., "noise") of the fMRI BOLD signal that provided the tool needed.

\section{Spontaneous fluctuations in the fMRI BOLD signal}

A prominent feature of $\mathrm{fMRI}$ is the noisiness of the raw BOLD signal (Fig. $1 \mathrm{~B}$ ), prompting researchers to average their data to increase the signal-to-noise ratio. As first shown by Bharat Biswal et al. (1995) in the human somatomotor system, a considerable fraction of this variance (i.e., noise) in the BOLD signal in the frequency range $<0.1 \mathrm{~Hz}$ exhibits striking patterns of coherence within known brain systems (Fig. 1C).

The significance of this observation was brought forcefully to our attention when Michael Greicius et al. (2003) at Stanford University looked at the patterns of coherence in the DMN elicited by placing a region of interest in either the posterior cingulate cortex (Fig. $1 A$, yellow arrow) or the ventral medial prefrontal cortex (Fig. 1A, orange arrow). The resulting time-activity curves (Fig. $1 B$ ) reflected a pattern of coherence within the entire DMN (Fig. 1C). Similar patterns of resting state coherence have now been documented in most cortical systems in the human brain [for example, see the studies by Fox and Raichle (2007), Smith et al. (2009)], as well as in their subcortical connections (Zhang et al., 2008).

A number of additional observations make these surprising patterns of spatial coherence of interest. First, they appear to 


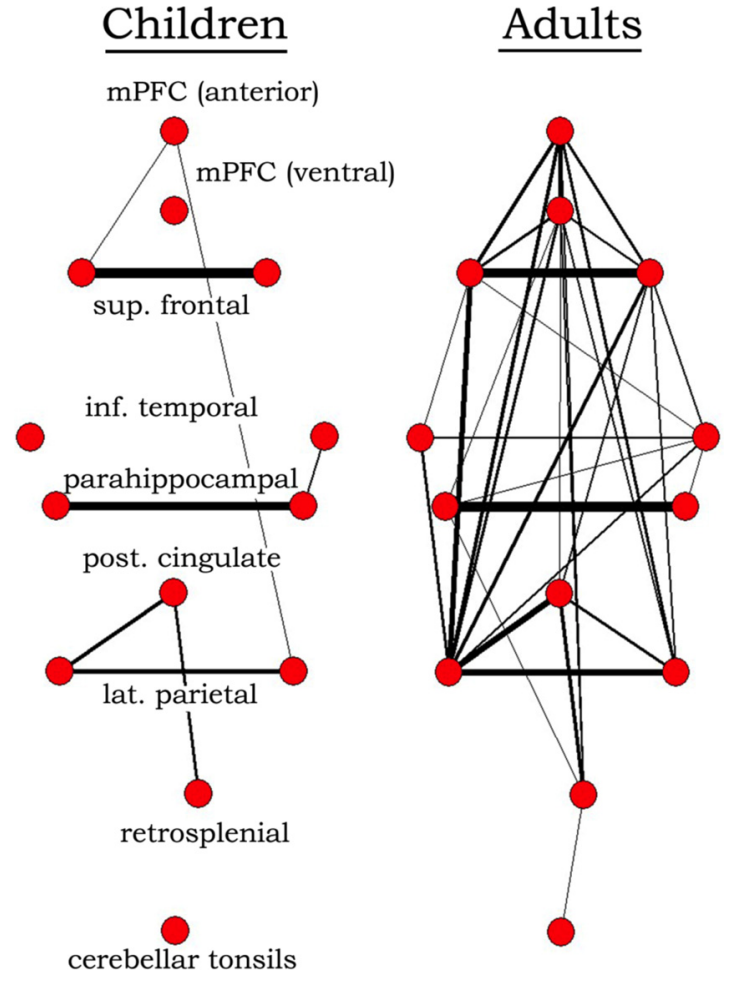

Figure 2. A graphic visualization of the correlation matrix within nodes of the DMN is presented in children (aged 7-9) on the left and adults (aged 21-31) on the right. The width of the line between two nodes depicts connection strength based on coherence of the resting-state fMRI BOLD signal (see Fig. 1). Noteworthy in these data is the differences in resting-state functional connectivity that accrue as the result of brain maturation. These data were reproduced with permission from D. A. Fair et al. (2008). inf., Inferior; lat., lateral; post., posterior; sup., superior.

transcend levels of consciousness, being present under anesthesia in humans (Greicius et al., 2008), monkeys (Vincent et al., 2007), and rats (Lu et al., 2007) (although in this study, as the level of anesthesia was increased the strength of coherence between the two cerebral hemispheres was diminished and finally eliminated). They are also present during the early stages of sleep in humans (Fukunaga et al., 2006; Larson-Prior et al., 2009). These observations make it unlikely that the patterns of coherence and the intrinsic activity they represent are primarily the result of unconstrained, conscious cognition, i.e., mind-wandering or day dreaming (Christoff et al., 2009).

Second, resting state patterns of coherence respect patterns of anatomical connectivity in both monkeys (Vincent et al., 2007) and humans (Zhang et al., 2009), but they are not constrained by these anatomical connections (Vincent et al., 2007; Zhang et al., 2008). For example, the absence of monosynaptic connections between right and left primary visual cortex in the monkey (Vincent et al., 2007) does not preclude the existence of functional connectivity as expressed in the maps of resting state coherence.

Third, the strength of coherence between nodes within systems increases during development in humans. Illustrative in this regard is the DMN (Fig. 2). This observation is consistent with the role of experience and, possibly, spontaneous activity itself [for example, see the studies by Yuste (1997) and Huberman et al. (2008)] in sculpting and maintaining these functional relationships in the human brain.

Finally, spontaneous fluctuations in the BOLD signal contribute significantly to both variability in evoked signals (Fox et al., 2006) and to variability in the associated behavior (Fox et al.,
2007). These observations become important as we consider the neurophysiologic correlates of the spontaneous BOLD fluctuations. What follows is a brief description of the direction the neurophysiologic work is taking beginning with the electrical correlates of the fMRI BOLD signal.

\section{The neurophysiology of BOLD}

There has been an active effort to ascertain the electrical correlates of the fMRI BOLD signal [for summaries of this work from different perspectives, see the studies by Raichle and Mintun (2006), Khader et al. (2008), Logothetis (2008)]. The conclusion is that the fMRI BOLD signal is best correlated with local field potentials (LFPs). LFPs are complex signals arising from the integrated electrical activity in presynaptic and postsynaptic terminals of the brain and are recorded with microelectrodes placed within brain tissue. Brain electrical activity recorded from the scalp with EEG or from the surface of the brain with electrocorticography (ECoG) constitutes a summation of a population of LFPs. LFPs are usually described in terms of their band-limited frequency components $(\delta, 1-4 \mathrm{~Hz}$; ̀̀, $4-8 \mathrm{~Hz} ; \alpha, 8-12 \mathrm{~Hz} ; \beta$, 12-24 Hz; and, $\left.\gamma, 24-80{ }^{+} \mathrm{Hz}\right)$.

Given the relationship between LFPs and BOLD, it is important here to focus on those LFP phenomena that exhibit frequencies similar to that of spontaneous BOLD fluctuations (i.e., 0.1-4.0 Hz). Two LFP phenomena fall into this category: fluctuations in the power of higher frequencies where particular attention has been paid to the gamma frequency band because of its association with cognition (Fries, 2009; Uhlhaas et al., 2009); and raw frequencies that approximate that of the spontaneous BOLD signal. These include the $\delta$ band $(1-4 \mathrm{~Hz})$ and infra-slow fluctuations or ISFs (Monto et al., 2008). ISFs are centered between 0.01 and $0.1 \mathrm{~Hz}$ (Vanhatalo et al., 2004; Monto et al., 2008) in the LFP frequency spectrum. These electrical potentials vary so slowly that they are sometimes called direct current (DC) potentials. ISFs are much less often recorded because of the amplifier requirements and concerns about artifacts (Khader et al., 2008). The $\delta$ frequency band and the ISFs have been combined and referred to as slow cortical potentials or SCPs (Rockstroh et al., 1989). Because it is likely that this envelope of frequencies is not functionally homogeneous (Steriade et al., 1993; Petersen et al., 2003; Watson et al., 2008) it is important to understand exactly what is reported. As these references indicate, an important additional phenomenon falls into this frequency range, namely "up and down states," which have important effects on neuronal function and behavior through rhythmic changes in cell excitability.

The research shows that the spontaneous fluctuations in the BOLD signal are best correlated with LFP activity in the range of the SCPs ( $\mathrm{Lu}$ et al., 2007; He et al., 2008). Indeed, failure to consider SCPs in seeking electrical correlates of the BOLD signal have led some (Leopold, 2009; Sirotin and Das, 2009) to the erroneous conclusion that the BOLD signal and its metabolic/ vascular underpinnings can operate independent of the brain's electrical activities. As is the case with the BOLD signal (see above) the spatial patterns of coherence exhibited by SCPs are maintained across levels of consciousness ranging from wakefulness to REM and slow-wave sleep (He et al., 2008) and during anesthesia ( $\mathrm{Lu}$ et al., 2007). In contrast, power in the gamma frequency band is only correlated spatially with the BOLD signal during wake and REM sleep (He et al., 2008) (see also Nir et al., 2008). This finding is consistent with the role of gamma-band coherence in the mental activities associated with conscious awareness (Fries, 2009; Uhlhaas et al., 2009). 


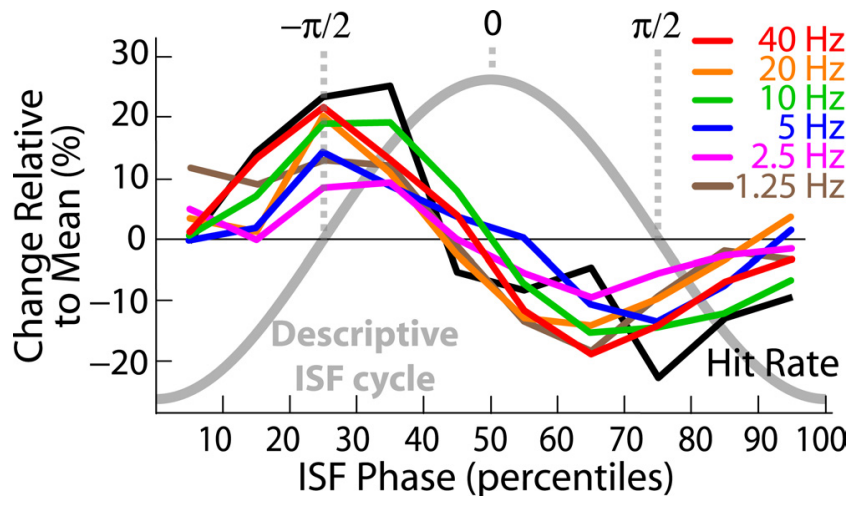

Figure 3. A depiction of cross-frequency coupling of $\mathrm{EEG}$ frequencies from 1 to $40 \mathrm{~Hz}$ within the phase of ISF. The thick gray line denotes a descriptive ISF cycle. It should be noted that the correlation of the $1-40 \mathrm{~Hz}$ oscillation amplitudes (colored lines) with the ISF is similar to that of the behavioral data (black line). This figure was reproduced with permission from S. Monto et al. (2008).

\section{A broader view}

Knowing that SCPs and spontaneous fluctuations in the BOLD signal are related provides a bridge to a highly relevant, rich, and diverse neurophysiologic literature on low-frequency oscillations/fluctuations [for example, see the studies by Rockstroh et al. (1989), Varela et al. (2001), Buzsáki and Draguhn (2004), Monto et al. (2008), and Schroeder and Lakatos (2009)]. Emerging from this extensive literature are several important themes.

First, SCPs and their BOLD counterpart (which includes optical imaging techniques) represent highly organized fluctuations in cortical excitability whose phase affects both evoked responses (Arieli et al., 1996; Fiser et al., 2004; Fox et al., 2006) and behavioral performance (Fox et al., 2007; Lakatos et al., 2008; Monto et al., 2008). Entrainment of SCPs to an expected, predictable stimulus [for example, see the studies by Lakatos et al. (2008), Montemurro et al. (2008), Gao et al. (2009), and Sirotin and Das (2009)] is an attractive means of matching predictions instantiated in intrinsic activity with the natural regularities of the environment (Bressler et al., 2008; Schroeder and Lakatos, 2008), a theme complementary to the concept of the "proactive" brain (Ingvar, 1985; Bar, 2009). An alternate state exists, as Schroeder and Lakatos (2008) posit when circumstances are unpredictable. Here, the brain may suppress low-frequency oscillations which, I would posit, may be seen as activity decreases in the DMN (Fig. 1A) (Fransson, 2006). This formulation provides one way of thinking about the give and take that exists between the DMN and what we have dubbed the task-positive network, a relationship instantiated even in the resting state (Fox et al., 2005, 2009; Popa et al., 2009).

Second, SCPs exhibit a remarkable relationship with other elements of the frequency spectrum of brain electrical activity (Monto et al., 2008) (Fig. 3) including the spiking activity of neurons (Montemurro et al., 2008). This cross-frequency coupling (i.e., nesting), with SCPs serving an overarching coordinating role within and across systems, provides the basis for integration in both space and time. One of the potential results of this, of course, might well be the emergence of consciousness ( $\mathrm{He}$ and Raichle, 2009).

As we move forward, the scope of the inquiry will undoubtedly expand even further into the realm of cell biology where events related to ion channel proteins, synaptic receptors, components of signal transduction pathways (Marder and Goaillard, 2006), and even cellular redox states (Vern et al., 1998) exhibit temporal dynamics very similar to the work reviewed above. Integrating across these many levels of analysis will obviously be challenging. Help will come from theoretical modeling approaches where creative work has already begun (Holcman and Tsodyks, 2006; Ghosh et al., 2008; Bullmore and Sporns, 2009). For all, the road ahead looks most exciting.

\section{References}

Ackermann RF, Finch DM, Babb TL, Engel J Jr (1984) Increased glucose utilization during long-duration recurrent inhibition of hippocampal pyramidal cells. J Neurosci 4:251-264.

Ames A 3rd (2000) CNS energy metabolism as related to function. Brain Res Rev 34:42-68.

Arieli A, Sterkin A, Grinvald A, Aertsen A (1996) Dynamics of ongoing activity: explanation of the large variability in evoked cortical responses. Science 273:1868-1871.

Attwell D, Laughlin SB (2001) An energy budget for signaling in the grey matter of the brain. J Cereb Blood Flow Metab 21:1133-1145.

Bandettini PA, Wong EC, Hinks RS, Tikofsky RS, Hyde JS (1992) Time course EPI of human brain function during task activation. Magn Reson Med 25:390-397.

Bar M (2009) The proactive brain: memory for predictions. Philos Trans R Soc Lond B Biol Sci 364:1235-1243.

Binder JR, Frost JA, Hammeke TA, Bellgowan PS, Rao SM, Cox RW (1999) Conceptual processing during the conscious resting state. A functional MRI study. J Cogn Neurosci 11:80-95.

Biswal B, Yetkin FZ, Haughton VM, Hyde JS (1995) Functional connectivity in the motor cortex of resting human brain using echo-planar MRI Magn Reson Med 34:537-541.

Bressler SL, Tang W, Sylvester CM, Shulman GL, Corbetta M (2008) Topdown control of human visual cortex by frontal and parietal cortex in anticipatory visual spatial attention. J Neurosci 28:10056-10061.

Brown TG (1914) On the nature of the fundamental activity of the nervous centres; together with an analysis of the conditioning of rhythmic activity in progression, and a theory of the evolution of function in the nervous system. J Physiol 48:18-46.

Buckner RL, Andrews-Hanna JR, Schacter DL (2008) The brain's default network: anatomy, function, and relevance to disease. Ann N Y Acad Sci 1124:1-38.

Bullmore E, Sporns O (2009) Complex brain networks: graph theoretical analysis of structural and functional systems. Nat Rev Neurosci 10:186-198.

Buzsáki G, Draguhn A (2004) Neuronal oscillations in cortical networks. Science 304:1926-1929.

Buzsáki G, Kaila K, Raichle M (2007) Inhibition and brain work. Neuron 56:771-783.

Chatton JY, Pellerin L, Magistretti PJ (2003) GABA uptake into astrocytes is not associated with significant metabolic cost: implications for brain imaging of inhibitory transmission. Proc Nat Acad Sci USA 100: $12456-12461$.

Christoff K, Gordon AM, Smallwood J, Smith R, Schooler JW (2009) Experience sampling during fMRI reveals default network and executive system contributions to mind wandering. Proc Natl Acad Sci U S A 106:8719-8724.

Clarke DD, Sokoloff L (1999) Circulation and energy metabolism of the brain. In: Basic neurochemistry. Molecular, cellular and medical aspects, Ed 6 (Agranoff BW, Siegel GJ, eds), pp 637-670. Philadelphia: Lippincott-Raven.

Creutzfeldt OD (1974) Neurophysiological correlates of different functional states of the brain. In: Brain work: the coupling of function, metabolism, and blood flow in the brain. Proceedings of the Alfred Benzon Symposium VIII (Ingvar DH, Lassen NA, eds), pp 21-47. Copenhagen: Munksgaard.

Fair DA, Cohen AL, Dosenbach NU, Church JA, Miezin FM, Barch DM, Raichle ME, Petersen SE, Schlaggar BL (2008) The maturing architecture of the brain's default network. Proc Natl Acad Sci U S A 105:4028-4032.

Fiser J, Chiu C, Weliky M (2004) Small modulation of ongoing cortical dynamics by sensory input during natural vision. Nature 431:573-578.

Fox MD, Raichle ME (2007) Spontaneous fluctuations in brain activity observed with functional magnetic resonance imaging. Nat Rev Neurosci 8:700-711.

Fox MD, Snyder AZ, Vincent JL, Corbetta M, Van Essen DC, Raichle ME 
(2005) The human brain is intrinsically organized into dynamic, anticorrelated functional networks. Proc Natl Acad Sci U S A 102:9673-9678.

Fox MD, Snyder AZ, Zacks JM, Raichle ME (2006) Coherent spontaneous activity accounts for trial-to-trial variability in human evoked brain responses. Nat Neurosci 9:23-25.

Fox MD, Snyder AZ, Vincent JL, Raichle ME (2007) Intrinsic fluctuations within cortical systems account for intertrial variability in human behavior. Neuron 56:171-184.

Fox MD, Zhang D, Snyder AZ, Raichle ME (2009) The global signal and observed anticorrelated resting state brain networks. J Neurophysiol 101:3270-3283

Frahm J, Bruhn H, Merboldt KD, Hänicke W (1992) Dynamic MR imaging of human brain oxygenation during rest and photic stimulation. J Magn Reson Imaging 2:501-505.

Fransson P (2006) How default is the default mode of brain function? Further evidence from intrinsic BOLD signal fluctuations. Neuropsychologia 44:2836-2845.

Fries P (2009) Neuronal gamma-band synchronization as a fundamental process in cortical computation. Annu Rev Neurosci 32:209-224.

Fukunaga M, Horovitz SG, van Gelderen P, de Zwart JA, Jansma JM, Ikonomidou VN, Chu R, Deckers RH, Leopold DA, Duyn JH (2006) Largeamplitude, spatially correlated fluctuations in BOLD fMRI signals during extended rest and early sleep stages. Magn Reson Imaging 24:979-992.

Gao L, Meng X, Ye C, Zhang H, Liu C, Dan Y, Poo MM, He J, Zhang X (2009) Entrainment of slow oscillations of auditory thalamic neurons by repetitive sound stimuli. J Neurosci 29:6013-6021.

Ghosh A, Rho Y, McIntosh AR, Kötter R, Jirsa VK (2008) Noise during rest enables the exploration of the brain's dynamic repertoire. PLoS Comput Biol 4:e1000196.

Greicius MD, Krasnow B, Reiss AL, Menon V (2003) Functional connectivity in the resting brain: a network analysis of the default mode hypothesis. Proc Natl Acad Sci U S A 100:253-258.

Greicius MD, Kiviniemi V, Tervonen O, Vainionpää V, Alahuhta S, Reiss AL, Menon V (2008) Persistent default-mode network connectivity during light sedation. Hum Brain Mapp 29:839-847.

Hagmann P, Cammoun L, Gigandet X, Meuli R, Honey CJ, Wedeen VJ, Sporns O (2008) Mapping the structural core of human cerebral cortex. PLoS Biol 6:e159.

He BJ, Raichle ME (2009) The fMRI signal, slow cortical potential and consciousness. Trends Cogn Sci 13:302-309.

He BJ, Snyder AZ, Zempel JM, Smyth MD, Raichle ME (2008) Electrophysiological correlates of the brain's intrinsic large-scale functional architecture. Proc Natl Acad Sci U S A 105:16039-16044.

Holcman D, Tsodyks M (2006) The emergence of Up and Down states in cortical networks. PLoS Comput Biol 2:e23.

Huberman AD, Feller MB, Chapman B (2008) Mechanisms underlying development of visual maps and receptive fields. Annu Rev Neurosci 31:479-509.

Ingvar DH (1985) "Memory of the future": an essay on the temporal organization of conscious awareness. Hum Neurobiol 4:127-136.

Kevles BH (1997) Naked to the bone. Medical imaging in the twentieth century. New Brunswick, NJ: Rutgers UP.

Khader P, Schicke T, Röder B, Rösler F (2008) On the relationship between slow cortical potentials and BOLD signal changes in humans. Int J Psychophysiol 67:252-261.

Kuhn TS (1996) The Structure of scientific revolutions, Ed 3. Chicago: University of Chicago.

Kwong KK, Belliveau JW, Chesler DA, Goldberg IE, Weisskoff RM, Poncelet BP, Kennedy DN, Hoppel BE, Cohen MS, Turner R (1992) Dynamic magnetic resonance imaging of human brain activity during primary sensory stimulation. Proc Natl Acad Sci U S A 89:5675-5679.

Lakatos P, Karmos G, Mehta AD, Ulbert I, Schroeder CE (2008) Entrainment of neuronal oscillations as a mechanism of attentional selection. Science 320:110-113.

Larson-Prior LJ, Zempel JM, Nolan TS, Prior FW, Snyder AZ, Raichle ME (2009) Cortical network functional connectivity in the descent to sleep. Proc Natl Acad Sci U S A 106:4489-4494.

Lennie P (2003) The cost of cortical computation. Curr Biol 13:493-497.

Leopold DA (2009) Neuroscience: pre-emptive blood flow. Nature 457: 387-388.

Llinas R (2001) I of the vortex. Cambridge, MA: MIT.
Logothetis NK (2008) What we can do and what we cannot do with fMRI Nature 453:869-878.

Lu H, Zuo Y, Gu H, Waltz JA, Zhan W, Scholl CA, Rea W, Yang Y, Stein EA (2007) Synchronized delta oscillations correlate with the resting-state function MRI signal. Proc Natl Acad Sci U S A 104:18265-18269.

Magistretti PJ, Chatton JY (2005) Relationship between L-glutamateregulated intracellular $\mathrm{Na}+$ dynamics and ATP hydrolysis in astrocytes. J Neural Transm 112:77-85.

Marder E, Goaillard JM (2006) Variability, compensation and homeostasis in neuron and network function. Nat Rev Neurosci 7:563-574.

Mazoyer B, Zago L, Mellet E, Bricogne S, Etard O, Houdé O, Crivello F, Joliot M, Petit L, Tzourio-Mazoyer N (2001) Cortical networks for working memory and executive functions sustain the conscious resting state in man. Brain Res Bull 54:287-298.

McCasland JS, Hibbard LS (1997) GABAergic neurons in barrel cortex show strong, whisker-dependent metabolic activation during normal behavior. J Neurosci 17:5509-5527.

Montemurro MA, Rasch MJ, Murayama Y, Logothetis NK, Panzeri S (2008) Phase-of-firing coding of natural visual stimuli in primary visual cortex. Curr Biol 18:375-380.

Monto S, Palva S, Voipio J, Palva JM (2008) Very slow EEG fluctuations predict the dynamics of stimulus detection and oscillation amplitudes in humans. J Neurosci 28:8268-8272.

Nir Y, Mukamel R, Dinstein I, Privman E, Harel M, Fisch L, Gelbard-Sagiv H, Kipervasser S, Andelman F, Neufeld MY, Kramer U, Arieli A, Fried I, Malach R (2008) Interhemispheric correlations of slow spontaneous neuronal fluctuations revealed in human sensory cortex. Nat Neurosci 11:1100-1108.

Ogawa S, Tank DW, Menon R, Ellermann JM, Kim SG, Merkle H, Ugurbil K (1992) Intrinsic signal changes accompanying sensory stimulation: functional brain mapping with magnetic resonance imaging. Proc Natl Acad Sci U S A 89:5951-5955.

Patel AB, de Graaf RA, Mason GF, Rothman DL, Shulman RG, Behar KL (2005) The contribution of GAGA to glutamate/glutamine cycling and energy metabolism in the rat cortex in vivo. Proc Natl Acad Sci U S A 102:5588-5593.

Pellerin L, Magistretti PJ (1997) Glutamate uptake stimulates $\mathrm{Na}+, \mathrm{K}+$ ATPase activity in astrocytes via activation of a distinct subunit highly sensitive to ouabain. J Neurochem 69:2132-2137.

Petersen CC, Hahn TT, Mehta M, Grinvald A, Sakmann B (2003) Interaction of sensory responses with spontaneous depolarization in layer $2 / 3$ barrel cortex. Proc Natl Acad Sci U S A 100:13638-13643.

Popa D, Popescu AT, Paré D (2009) Contrasting activity profile of two distributed cortical networks as a function of attentional demands. J Neurosci 29:1191-1201.

Raichle M (2000) A brief history of human functional brain mapping. In: Brain mapping: the systems (Toga A, Mazziotta J, eds), pp 33-75. San Diego: Academic.

Raichle ME (2009) A brief history of human brain mapping. Trends Neurosci 32:118-126.

Raichle ME, Mintun MA (2006) Brain work and brain imaging. Annu Rev Neurosci 29:449-476.

Raichle ME, Snyder AZ (2007) A default mode of brain function: a brief history of an evolving idea. Neuroimage 37:1083-1090.

Raichle ME, MacLeod AM, Snyder AZ, Powers WJ, Gusnard DA, Shulman GL (2001) A default mode of brain function. Proc Natl Acad Sci U S A 98:676-682.

Rockstroh B, Elbert T, Canavan AG, Lutzenberger W, Birbaumer N (1989) Slow cortical potentials and behavior, Ed 2. Baltimore: Urban and Schwarzenberg.

Schroeder CE, Lakatos P (2008) Low-frequency neuronal oscillations as instruments of sensory selection. Trends Neurosci 32:9-18.

Sherrington CS (1906) The integrative action of the nervous system, Ed 1. New Haven, CT: Yale UP.

Shulman GL, Fiez JA, Corbetta M, Buckner RL, Miezin FM, Raichle ME, Petersen SE (1997) Common blood flow changes across visual tasks: II. Decreases in cerebral cortex. J Cogn Neurosci 9:648-663.

Shulman RG, Hyder F, Rothman DL (2001) Cerebral energetics and the glycogen shunt: neurochemical basis of functional imaging. Proc Natl Acad Sci U S A 98:6417-6422.

Shulman RG, Rothman DL, Behar KL, Hyder F (2004) Energetic basis of 
brain activity: implications for neuroimaging. Trends Neurosci 27:489495.

Sibson NR, Dhankhar A, Mason GF, Behar KL, Rothman DL, Shulman RG (1997) In vivo ${ }^{13} \mathrm{C}$ NMR measurements of cerebral glutamate synthesis as evidence for glutamate-glutamine cycling. Proc Natl Acad Sci U S A 94:2699-2704.

Sibson NR, Dhankhar A, Mason GF, Rothman DL, Behar KL, Shulman RG (1998) Stoichiometric coupling of brain glucose metabolism and glutamatergic neuronal activity. Proc Natl Acad Sci U S A 95:316-321.

Sirotin YB, Das A (2009) Anticipatory haemodynamic signals in sensory cortex not predicted by local neuronal activity. Nature 457:475-479.

Smith SM, Fox PT, Miller KL, Glahn DC, Fox PM, Mackay CE, Filippini N, Watkins KE, Toro R, Laird AR, Beckmann CF (2009) Correspondence of the brain's functional architecture during activation and rest. Proc Natl Acad Sci U S A 106:13040-13045.

Sokoloff L, Mangold R, Wechsler RL, Kenney C, Kety SS (1955) The effect of mental arithmetic on cerebral circulation and metabolism. J Clin Invest 34:1101-1108.

Steriade M, Nuñez A, Amzica F (1993) A novel slow ( <1 Hz) oscillation of neocortical neurons in vivo: depolarizing and hyperpolarizing components. J Neurosci 13:3252-3265.

Uhlhaas PJ, Pipa G, Lima B, Melloni L, Neuenschwander S, Nikolić D, Singer W (2009) Neural synchrony in cortical networks: history, concept and current status. Front Integr Neurosci 3:17.

Vanhatalo S, Palva JM, Holmes MD, Miller JW, Voipio J, Kaila K (2004) Infraslow oscillations modulate excitability and interictal epileptic activity in the human cortex during sleep. Proc Natl Acad Sci U S A 101: 5053-5057.

Varela F, Lachaux JP, Rodriguez E, Martinerie J (2001) The brainweb:
Phase synchronization and large-scale integration. Nat Rev Neurosci 2:229-239.

Vern BA, Leheta BJ, Juel VC, LaGuardia J, Graupe P, Schuette WH (1998) Slow oscillations of cytochrome oxidase redox state and blood volume in unanesthetized cat and rabbit cortex. Interhemispheric synchrony. In: Oxygen transport to tissue, pp 561-570. New York: Plenum.

Vincent JL, Patel GH, Fox MD, Snyder AZ, Baker JT, Van Essen DC, Zempel JM, Snyder LH, Corbetta M, Raichle ME (2007) Intrinsic functional architecture in the anaesthetized monkey brain. Nature 447:83-86.

Waldvogel D, van Gelderen P, Muellbacher W, Ziemann U, Immisch I, Hallett M (2000) The relative metabolic demand of inhibition and excitation. Nature 406:995-998.

Watson BO, MacLean JN, Yuste R (2008) UP states protect ongoing cortical activity from thalamic inputs. PLoS One 3:e3971.

Webb S (1990) From the watching of shadows. New York: Adam Hilger.

Wong-Riley MT (1989) Cytochrome oxidase: an endogenous metabolic marker for neuronal activity. Trends Neurosci 12:94-101.

Yuste R (1997) Introduction: spontaneous activity in the developing central nervous system. Semin Cell Dev Biol 8:1-4.

Yuste R, MacLean JN, Smith J, Lansner A (2005) The cortex as a central pattern generator. Nat Rev Neurosci 6:477-483.

Zhang D, Snyder AZ, Fox MD, Sansbury MW, Shimony JS, Raichle ME (2008) Intrinsic functional relations between human cerebral cortex and thalamus. J Neurophysiol 100:1740-1748.

Zhang D, Snyder AZ, Shimony JS, Fox MD, Raichle ME (2009) Noninvasive functional and structural connectivity mapping of the human thalamocortical system. Cereb Cortex. Advance online publication. Retrieved Sept. 3, 2009. doi:10.1093/cercor/bhp182. 